Literature Reviews

\title{
Cryptosporidiosis in Ruminants: Update and Current Therapeutic Approaches
}

\author{
Ceren Dinler and Bulent Ulutas \\ Department of Internal Medicine, Faculty of Veterinary Medicine, Adnan Menderes University, Aydin, Turkey
}

\author{
Article history \\ Received:11-04-2017 \\ Revised: 29-05-2017 \\ Accepted: 15-06-2017 \\ Corresponding Author: \\ Bulent Ulutas \\ Department of Internal \\ Medicine, Faculty of Veterinary \\ Medicine, Adnan Menderes \\ University,Aydin, Turkey \\ E-mail: bulutas@adu.edu.tr
}

\begin{abstract}
Cryptosporidium species causes asymptomatic or mild to severe gastrointestinal disease in their broad range of host species. These host species include humans, domestic and wild animals worldwide. The importance of cryptosporidiosis in ruminants has been emphasised in recent years for not only mortality, delayed growth and economic losses in the farm but also zoonotic importance. So more than 200 substances have been tested against cryptosporidiosis, but none of them was able to eliminate the infection consistently. This article will focus on therapeutic interventions in neonatal ruminants against cryptosporidiosis including perspectives for new drugs.
\end{abstract}

Keywords: Cryptosporidium, Calf, Lamb, Kid, Treatment

\section{Introduction}

Cryptosporidium is an enteric protozoan parasite which causes gastrointestinal diseases on a different level. This species infects a wide range hosts including humans and animals worldwide. Cryptosporidium was first described in the laboratory mouse by Earnest Tyzzer in 1907. However, the clinical importance of this protozoan was not fully regarded in the medical and veterinary field for another 70 years (Tzipori and Ward, 2002). Bovine cryptosporidiosis was firstly documented in 1971 following identification of the parasites in an 8month-old calf with chronic diarrhoea (Panciera et al., 1971). Later, cryptosporidiosis was described in lambs with diarrhoea in Australia, but it could not considered to be the cause of the disease because of concurrent pathogenic bacterial infection (Barker and Carbonell, 1974). Finally, in the early 1980s, studies on natural and experimental infections revealed the role of the protozoan in diarrhoea in ruminants as a primary etiological agent (Robertson et al., 2013).

Cryptosporidium parvum affects many species of mammals that include human and it has considerable economic significance in farm animals, especially in the ruminant (Ryan and Hijjawi, 2015). Modern molecular methods are used to analyse the genetic profile of this parasite and new sub-species and genotypes of the parasite have been identified. Currently, 28 species have been recognised (Ryan et al., 2014; Hotchkiss et al., 2015) Different bovine species such as cattle, banteng, gayal, water buffalo and yaks were found susceptible to $C$. parvum, C. bovis, C. andersoni and C. ryanae. Also, small ruminants are susceptible to $C$. parvum, $C$. xiaoi and $C$. ubiquitous. It was reported that the primary source of the transmission of $C$. parvum to humans are ruminants such as cattle, goats and sheep and they have especially significant role in the human epidemics (Fayer, 1997; Thompson et al., 2005; Shahiduzzaman and Daugschies, 2012; Nasir et al., 2013).

The life cycle of parasite consists of six major developmental phases which are excystation, merogony, gametogonia, fertilisation, oocyst wall formation and sporogony. Oocysts of Cryptosporidium spp. can sporulate within host cells and when they passed the feces becomes infective. In natural and experimentally induced cases in neonates, C. parvum not only affect the distal small intestine but also can affect proximal small intestine and some part of the large intestine (Laurent et al., 1999; Constable, 2014). Some pathological changes can occur in affected animals intestine such as villus atrophy, villus degeneration, crypt hyperplasia, inflammatory infiltrations and microvillus degeneration. These changes cause maldigestion, malabsorption and osmotic imbalance (malabsorptive and secretor diarrhea) (Koudela and Jiří, 1997; McCole et al., 2000; Gookin et al., 2002; O'Handley and Olson, 2006). Because of all this, mild to moderate diarrhea its characteristic with watery, yellow or pale feces which contains mucus. Furthermore, the infected neonates can die in 3-4 weeks of life due to dehydration, weight loss, apathy, anorexia and energy deficit. On the other hand, Cryptosporidiosis is self-limiting in the neonates with strong immunity (Constable, 2014). 
In experimentally $C$. parvum infected neonatal calves, it was demonstrated that there are two periods of oocyst shedding, as prepatent and patent, ranging from 3-6 and 4-13 days respectively. In practice, even in 3 days of age oocyst excretion has been demonstrated. Which means, infection susceptibility presents immediately after birth of the calves. Oscillation of the prepatent period in lambs and goat kids is between 2-7 days and around 4 days, respectively. However, even the severity of clinical signs is reduced, the animal's susceptibility to infection continues in further age (de Graaf et al., 1999).

Because of its mortality rate, growth and developmental delaying effect and other reasons, Cryptosporidiosis is a disease with economic importance. Also, livestock, particular cattle are one of the most important reservoirs of zoonotic infections. The factors contribute the epidemiology of Cryptosporidium are extraction of the oocysts in large quantities, survival of the oocysts in warm and moist conditions for months, arising from the infection can be caused by a small number of oocysts, even from a single oocyst for susceptible individuals (de Graaf et al., 1999; Ryan et al., 2014).

Cryptosporidiosis is a major problem for farm and public health since there are no effective treatment and prevention methods although many substances have been tested, no agent has been found to control or eliminate the cryptosporidiosis consistently. Only, oocyst shedding can be reduced by using some medicines. For effective control of infection, improving hygienic conditions and drug applications should be carried out in combination because no measure is sufficient alone against to cryptosporidiosis (de Graaf et al., 1999; Shahiduzzaman and Daugschies, 2012). New treatment approach such as drug treatment and alternative therapy options will be addressed in this review.

\section{Drug Treatment for Cryptosporidiosis in Ruminants}

Treatment of cryptosporidiosis in farms falls broadly into three categories: Anti-Cryptosporidial drug therapy, supportive therapy and reduction of environmental oocyst load. One or more of these therapeutic options are used for controlling the infection. Mostly, anti-cryptosporidial agent trials were performed on laboratory animals. Although there are many promising agents in vitro or in vivo models, none of these agents is useful for the elimination of cryptosporidiosis from the infected animal. Some conditions such as the immune status of the animals, concomitant other infectious agents and effective supportive treatment affect the clinical and parasitological responses to treatment. However, drugs that have been applied with more or less efficiency reviewed here for ruminants (Shahiduzzaman and Daugschies, 2012).

\section{Azithromycin}

Azithromycin is a macrolide antibiotic, which has variable efficiency and has been used for the treatment of cryptosporidiosis of immune suppressed animals and humans (Rehg, 1991; Holmberg et al., 1998). Azithromycin shows the antibacterial mode of action by inhibition of protein synthesis (Armson et al., 2003).

Elitok et al. (2005) randomised 50 naturally infected calves with $C$. parvum and medicated orally with azithromycin at the doses of 500,1000, 1500 and 2,000 mg PO once daily for 7 days. On days 14 and 21 following the cessation of the drug application calves were monitored in terms of drug efficiency. The most effective doses for reduction of oocyst count was found as 1,500 and 2,000 $\mathrm{mg} \mathrm{d}^{-1}$. Nasir et al. (2013) and Kumar et al. (2015) reported that Azithromycin (1500 mg day ${ }^{-1}$ for 7 days) therapy of cryptosporidiosis caused significant clinical improvement and reduction of oocyst count in naturally infected calves.

Despite above these studies, novel data from clinical trials aren't sufficient for control of cryptosporidiosis in calves. Because these studies were performed field conditions and animals may be re-infection. Also, Azithromycin is expensive in many countries so it may not be economical for farms (Shahiduzzaman and Daugschies, 2012).

\section{Paromomycin}

Paromomycin is an aminoglycoside and most of the medicine is removed from the stool in oral usage because of its poor absorption from the intestine (Johnson et al., 2000).

Grinberg et al. (2002), reported a significant reduction in stool frequency and oocyst excretion after application of paromomycin at $100 \mathrm{mg} \mathrm{kg}^{-1}$ orally, once a day for 10 days, but oocysts excretion and diarrhoea started following cessation of the drug in naturally infected calves. Also, Masood et al. (2013) reported that paromomycin (25 mg kg-1 $\mathrm{BW}$, for 5 days) reduced quantity and duration of oocyst shedding in experimentally infected calves.

A previous study indicated that paromomycin $(25 \mathrm{mg}$ $\mathrm{kg}^{-1}$ ) significantly decreased to faecal oocyst count starting from a post treatment 3rd day in naturally infected kids and lambs (Shafiq et al., 2015). Also, Viu et al. (2000) indicated that paromomycin application to lambs at 100 $\mathrm{mg} \mathrm{kg}^{-1} \mathrm{BW}$ per day for three consecutive days or 200 $\mathrm{mg} \mathrm{kg}{ }^{-1} \mathrm{BW}$ per day for two days reduced both oocyst shedding and severity of diarrhoea.

Mancassola et al. (1995) used treated the experimentally infected goats by using paromomycin and observed that antibodies to Cryptosporidium parvum developed. Besides, the increase of antibody was associated with protection and prevention of oocyst shedding. 
In a comparative study, a single dose of $50 \mathrm{mg} \mathrm{kg}^{-1}$ body weight of metronidazole caused a significant decrease in oocyst count per gram faeces from 3rd-day post treatment. Moreover, Metronidazole was found more effective than paromomycin in naturally infected lambs and kids (Shafiq et al., 2015). On the other hand, Masood et al. (2013) reported that Paromomycin to be the more valuable than metronidazole for the treatment of Cryptosporidium infection in cattle based on the clinical trials.

The effect of Paromomycin on the reduction of clinical signs and oocyst excretion does not seem consistent although the data are promising. (Ritchie and Becker, 1994). Also, of major concern in the testing of the clinical efficacy of any drug are its toxic effects. Paromomycin is an aminoglycoside and so might cause nephrotoxicity and ototoxicity (Johnson et al., 2000). This product is not used in ruminants generally.

\section{Nitazoxanide}

Nitazoxanide (NTZ) is an antimicrobial substance that has been applied for antiparasitic treatment in dogs, cats, sheep and goats (Euzeby et al., 1980; Gookin et al., 2001; Viel et al., 2007). Additionally, NTZ has been FDA approved for human use for treatment of cryptosporidiosis.

Sahu and Maiti (2015) reported that NTZ administered to calves at $15 \mathrm{mg} \mathrm{kg}^{-1} \mathrm{BW}$ twice a day for three consecutive days reduced both oocyst shedding and severity of diarrhoea as reported by Viel et al. (2007) in experimentally infected goats. On the other hand, Schnyder et al. (2009) reported that the effect of NTZ on clinical severity or oocyst excretion in the experimentally Cryptosporidium infection was less than expected.

Treatment efficiency of NTZ is controversial. However, it has consistent side effects such as stomachache, headache and emesis. The oral administration of NTZ to calves $\left(15 \mathrm{mg} \mathrm{kg}^{-1} \mathrm{BW}\right.$, BID) affected the mucous membranes of the gastrointestinal tract. Similar effects were also observed in piglets (Theodos et al., 1998), cats (Gookin et al., 2001) and neonatal ruminants (Viel et al., 2007; Schnyder et al., 2009).

Oral administration at a dose of $75-400 \mathrm{mg} \mathrm{kg}{ }^{-1}$ BW in the sheep caused to mild diarrhea that lasts for about 24-36 $\mathrm{h}$ and mild catarrhal inflammation. (Euzeby et al., 1980) Therefore, it is not recommended for either treatment or prophylaxis of cryptosporidiosis (Shahiduzzaman and Daugschies, 2012).

\section{Halofuginone Lactate}

Halofuginone lactate which is a synthetic product of the quinazolinone group with antiprotozoal activity, has received positive reports from studies related to the treatment of Cryptosporidiosis in veal calves (Lallemond et al., 2006) dairy calves (Villacorta et al.,
1991; Klein, 2008) and lambs (Naciri and Yvore, 1989). Clinical studies showed that halofuginone had cryptosporidiastatic activity in the sporozoite and merozoite stages of C. parvum (Jarvie et al., 2005). Because of halofuginon delays the onset of infection decreases oocyst shedding and cryptosporidiosis severity, it has been recommended for both therapeutic and prophylactic use (Joachim et al., 2003; Jarvie et al., 2005).

According to Weber et al. (2016), halofuginone is approved for prophylaxis against cryptosporidiosis, but it showed no effect on the excretion of Cryptosporidium oocysts in calves. Conversely, there are different studies which halofuginone showed no effect on the course of infection concerning diarrhoea and dehydration. (Lallemond et al., 2006) alternatively, seven days after the drug was withdrawn, oocysts appeared again in faeces, indicating re-infection (Shahiduzzaman and Daugschies, 2012).

In general, ruminants were cured with $0,1-0,12 \mathrm{mg}$ $\mathrm{kg}^{-1} \mathrm{BW}$ orally for 7 days. Also, halofuginone at the recommended dose $\left(0,1 \mathrm{mg} \mathrm{kg}^{-1}\right.$ for seven consecutive days) seems to restraints cryptosporidial reproduction rate and improves the development of immunity in lambs (Causape et al., 1999; Giadinis et al., 2007).

According to Chartier et al. (1999), the administration of halofuginone to 3-day old kids for 7-10 days decreased the prevalence and intensity of Cryptosporidium oocyst output when compared to control, particularly from 3 to 7 following the start of drug administration. Similarly, Giadinis et al. (2008) showed a reduction of oocyst shedding on days 5 and 7 following the beginning of administration at 1-2 day of age in kids.

Also, Petermann et al. (2014) reported that when given as a prophylactic treatment at $0,1 \mathrm{mg} \mathrm{kg}^{-1} \mathrm{BW}$ during 10 days in reducing oocyst shedding, diarrhoea and mortality in goat kid affected by C. parvum.

This drug is approved in Europe to treat calf cryptosporidiosis. The disadvantage of this product is that is must be given orally for 7 days from birth and this is not always practical, especially in beef suckler units. Also, it is vitally important that farmers be aware of the potential effects of overdosing as toxic effects have been shown at only twice the recommended dose. The product is also licensed for the treatment of diarrhoea due to cryptosporidiosis however it must not be given to dehydrated or inappetence animals (Robertson et al., 2013).

\section{Decoquinate}

Decoquinate is quinolone coccidiostat that found to have little activity against $C$. parvum in vitro or in vivo in suckling mice (Lindsay et al., 2000).

Redman and Fox (1993) found that decoquinate reduced the shedding of oocysts and the clinical signs in experimentally induced cryptosporidiosis in calves when 
decoquinate is used at $2 \mathrm{mg} \mathrm{kg}^{-1} \mathrm{BW}$ dose for 21 days. In contrast, decoquinate had no effect either on the shedding of oocysts or on the calves' clinical signs, in agreement with the results of Moore et al. (2003).

In kids, the decoquinate at $2,5 \mathrm{mg} \mathrm{kg}^{-1} /$ day for 21 days, although it did not eradicate cryptosporidiosis, it gave significant improvements, no diarrhoea and decrease in oocyst shedding (Mancassola et al., 1997).

Decoquinate is commonly used by producers to prevent cryptosporidiosis (Moore et al., 2003) but the practice should be reconsidered on account of its questionable efficacy.

\section{Alternative Therapy for Cryptosporidiosis in Ruminants}

The studies for alternative therapy which could be used as the anti-parasitic treatment had received considerable attention in recent years because of the increasing worldwide development of resistance to the synthetic drug in parasitic populations.

\section{Activated Charcoal and Wood Vinegar}

Activated charcoal can bind with various molecules and because of this, it is known as a universal adsorbent (Chandy and Sharma, 1998). For the removal of bacteria and bacterial toxins both in vitro and in vivo, it was reported that activated charcoal could be used effectively (Drucker et al., 1977; Pegues et al., 1979; Du et al., 1987; Gardiner et al., 1993).

In a study on experimentally infected calves, rapid clinical improvement and cessation of oocyst excretion revealed after a short time following treatment of activated charcoal that contains wood vinegar liquid (Watarai et al., 2008). These authors also set up in vitro experiments to explain the activity of the 2 components of the product. They observed that activated charcoal adsorbed $C$. parvum oocysts and that the number of $C$. parvum oocysts was lowered by the addition of increasing concentrations of wood vinegar.

In another study conducted in field condition, a product containing activated charcoal and wood vinegar liquid was given to goat kids at the dose rate of 3.75 $\mathrm{g} /$ day/kid (Obionekk ${ }^{\circledR}$ ) for defensive purposes. It was administered as a suspension in milk replacer twice or three times a day starting at the age of 3 days to the age of 17 days. Compared with the control group, oocyst excretion was significantly reduced when the product was given 3 times a day and clinical signs also significantly resolved whatever the rhythm of distribution (Paraud et al., 2011).

Consequently, this product may be helpful for the treatment and prevention of cryptosporidiosis in ruminants but it does not eradicate the disease.

\section{Nigella Sativa}

Nigella sativa seeds have been known with wide therapeutic effects. Its positive effects against skin diseases, jaundice, gastrointestinal problems, anorexia, conjunctivitis, dyspepsia, rheumatism, diabetes, hypertension, intrinsic haemorrhage, paralysis, amenorrhea, anorexia, asthma, cough, bronchitis, headache, fever, influenza and eczema have been reported (Forouzanfar et al., 2014).

Nigella sativa has been reported to have good anticoccidial activity with no harmful side effects in rabbits at a dose rate of $400 \mathrm{mg} \mathrm{kg}^{-1} \mathrm{BW}$ orally for 14 days (Baghdadi and Al-Mathal, 2011). In a study by Nasir et al. (2013) on the therapeutic efficacy of Nigella Sativa showed no effect on oocyst shedding in naturally infected dairy calves. Studies on the efficacy of Nigella Sativa against $C$. parvum are rare, but it has been shown to be effective as antihelminthic and anticoccidial (Nasir et al., 2013).

\section{Clinoptilolite (Zeolite)}

Clinoptilolite which is a natural zeolite is mineral mined from sedimentary deposits (Leung et al., 2007). Zeolites retain moisture due to the desorption of loosely bound water present on, or close to the external zeolite surface (Leggo et al., 2006). Clinoptilolite could modify appropriate environmental conditions of humidity for oocyst to sporulate and become infective and also it has got the immunomodulator effect for the host (Jurkic et al., 2013).

Ulutas et al. (2015) reported that in neonatal lambs infected with $C$. parvum that were receiving prophylactic clinoptilolite the appearance of diarrhea as well as duration and intensity of oocyte shedding was considerably reduced. In addition, the severity of cryptosporidiosis was reduced in the clinoptilolite group.

\section{Garlic (Allium Sativum-Garlicin)}

As an extract of garlic, garlicin has been confirmed to have multiple curative effects such as antimicrobial, antithrombotic, hypolipidemic and antitumor activities. Lately, some reports tested the effect of garlicin in the treatment of parasites such as toxoplasmosis, trichomoniasis and cryptosporidiosis (Huang et al., 2015).

Garlic was a convenient prophylactic and a promising therapeutic agent for cryptosporidiosis (Abdel Megeed et al., 2015). The efficacy of garlic in the prophylaxis and treatment of experimental cryptosporidiosis could be explained by a different mechanism. El-Shenawy and Hassan (2008) reported the enhancement of phagocytosis and an increase in natural killer cell activity which promoted the immune system function and strengthened the body's defence mechanism during the duration of treatment by garlic. Moreover, Masamha et al. (2010) found that Allium 
sativum disrupted the normal physiological functions of the parasite like morbidity and reproduction.

In a study by Abdel Megeed et al. (2015) on the therapeutic efficacy in naturally infected Buffalo calves of garlic showed it eradicated the Cryptosporidium oocysts from the faeces and almost no oocysts were detected in the faeces of garlic treatment group by the end of the study. Also, the same study showed that garlic was effective not only in reducing oocyst counts but also in making the health of the animals better.

Garlic offered a promising effect in the treatment of cryptosporidiosis and it is recommended to be used in the daily animal diet to give protective effects against parasites (Abdel Megeed et al., 2015).

\section{Conclusion}

Cryptosporidiosis is a parasitic intestinal disease of a wide variety of animals and humans. Major reservoirs of C. parvum are livestock, especially cattle and sheep. Transmission of the infection may be directly from animal to human or indirectly via a vehicle. A large number of small outbreaks associated with C. parvum in calves and in veterinarians or veterinary students that have been exposed to calf faeces are documented in the literature (Gait et al., 2008; Grinberg et al., 2011; Robertson et al., 2013). Most indirect transmission is drinking water and less often food has been associated with transmission of Cryptosporidium infection from animals to human populations. A birth cohort study conducted by a Global Network for the Study of Malnutrition and Enteric Diseases (MAL-ED) has assessed pathogen-specific burdens in diarrhoeal and non-diarrhoeal stool specimens from 2145 children aged 0-24 months in Africa, Asia and South America and also identified Cryptosporidium spp. as one of the five highest attributable burdens of diarrhoea in the first year of life (Platts-Mills et al., 2015; Ryan et al., 2016). Globally, Cryptosporidiosis is estimated to be responsible for the majority of deaths among children under 5 years of age (Ryan et al., 2016).

The importance of cryptosporidiosis in ruminants has been emphasised in recent years for not only mortality, delayed growth and economic losses in the farm but also zoonotic importance. The "One Health" approach to tackling the zoonotic disease, defined as "One Medicine" by Schwabe (1969), is a worldwide strategy to improve health and well-being though the mitigation and prevention of infection. Despite exhaustive attempts at chemotherapy, no effective treatment for cryptosporidiosis had been identified (Abdel Megeed et al., 2015). For example, halofuginone is licensed for the treatment of bovine cryptosporidiosis in several countries, but it is known to be relatively toxic and care must be taken not to exceed the claimed dose (Shahiduzzaman and Daugschies, 2012). Because of the limited availability of effective drugs, sanitary measures and good management are currently the most valid weapons in controlling this disease.

In conclusion, funding has recently been secured to study more closely the host-parasite interaction with the neonatal gut, to better understand the early response to infection. The new studies focused on mainly genetic characterization and protein analyses of the parasite. Bioinformatic and proteomics studies have recently gained increased recognition for this purpose. These studies will open the way for a more careful approach to chemotherapy for cryptosporidiosis in the near future. Thus it is the author's advice that primary aim at controlling the cryptosporidiosis in farms should be minimising the build-up of environmental contamination and reducing the clinical impact by optimising the neonatal environment and managing other enter pathogens until effective drugs are developed.

\section{Acknowledgement}

Any financial support was used to write this manuscript.

\section{Author's Contributions}

Ceren Dinle: Carried out literature research, writing and draft the review.

Bulent Ulutas: Supervision of the review, critical review and organise the manuscript period.

\section{Ethics}

This review is original and was not published elsewhere. It can be confirmed that all authors have read and approved the manuscript and no ethical issues involved.

\section{References}

Abdel Megeed, K.N., A.M. Hammam, G.H. Morsy, F.A.M. Khali and M.M.E. Seliem et al., 2015. Control of Cryptosporidiosis in buffalo calves using garlic (Allium sativum) and Nitazoxanide with special reference to some biochemical parameters. Global Veterinar., 14: 646-655.

DOI: 10.5829/idosi.gv.2015.14.05.94137.

Armson, A., R.A. Thompson and J.A. Reynoldson, 2003. A review of chemotherapeutic approaches to the treatment of cryptosporidiosis. Expert Rev. Anti. Infect. Therapy, 1: 297-305.

DOI: $10.1586 / 14787210.1 .2 .297$

Baghdadi, H.B. and E.M. Al-Mathal, 2011. Anticoccidial activity of Nigella sativa L. J. Food Agric. Envir., 9: 10-17.

Barker, I.K. and P.L. Carbonell, 1974. Cryptosporidium agni sp. n. from lambs and Cryptosporidium bovis sp. n. from a calf, with observations on the oocyst. Parasitol. Res., 44: 289-298. DOI: 10.1007/BF00366112 
Causape, A.C., C. Sanchez-Acedo, J. Quilez, E. del Cacho and M. Viu, 1999. Efficacy of halofuginone lactate against natural Cryptosporidium parvum infections in lambs. Res. Rev. Parasitol., 59: 41-46.

Chandy, T. and C.P. Sharma, 1998. Activated charcoal microcapsules and their applications. J. Biomater. Applic., 13: 128-157. DOI: $10.1177 / 088532829801300204$

Chartier, C., M.P. Mallereau and D. Lenfant, 1999. Halofuginone lactate in the control of cryptosporidiosis in neonate kids. Revue de Med. Vet., 150: 341-348.

Constable, P., 2014. Overview of cryptosporidiosis. Merck Vet. Manual.

de Graaf, D.C., E. Vanopdenbosch, L.M. Ortega-Mora, H. Abbassi and J.E. Peeters, 1999. A review of the importance of cryptosporidiosis in farm animals. Int. J. Parasitol., 29: 1269-1287. DOI: $10.1016 / \mathrm{S} 0020-7519(99) 00076-4$

Drucker, M.M., J. Goldhar, P.L. Ogra and E. Neter, 1977. The effect of attapulgite and charcoal on enterotoxicity of vibrio cholerae and Escherichia coli enterotoxins in rabbits. Infection, 5: 211-213. DOI: $10.1007 / \mathrm{BF} 01640782$

Du, X.N., Z. Niu, G.Z Zhou and Z.M. Li, 1987. Effect of activated charcoal on endotoxin adsorption. Part I. an in vitro study. Biomater., Artif. Cells Artif. Organs, 15: 229-235. DOI: 10.3109/10731198709118523

Elitok, B., O.M. Elitok and H. Pulat, 2005. Efficacy of azithromycin dihydrate in the treatment of cryptosporidiosis in naturally infected dairy calves. J. Vet. Intern. Med., 19: 590. DOI: 0891-6640/05/1904-0016

El-Shenawy, S.M. and N.S. Hassan, 2008. Comparative evaluation of the protective effect of selenium and garlic against liver and kidney damage induced by mercury chloride in the rats. Pharmacol. Rep., 60: 199-199. PMID: 18443381

Euzeby, J., S.P. Tep and J.F. Rossignol, 1980. Experimentation des proprietes anthelminthiques de la nitazoxanide chez le chien, le chat et les ovins. Rev. Med. Vet. Toulouse.

Fayer, R., 1997. Cryptosporidium and Cryptosporidiosis. 1st Edn., CRC Press, Boca Raton, Florida, pp: 251.

Forouzanfar, F., B.S.F. Bazzaz and H. Hosseinzadeh, 2014. Black cumin (Nigella sativa) and its constituent (thymoquinone): A review on antimicrobial effects. Iranian J. Basic Med. Sci., 17: 929-929. PMID: 4387228

Gait, R., R.H. Soutar, M. Hanson, C. Fraser and R. Chalmers, 2008. Outbreak of cryptosporidiosis among veterinary students. Vet. Record, 162: 843. DOI: $10.1136 /$ vr.162.26.843

Gardiner, K.R., N.H. Anderson, M.D.McCaigue, P.J. Erwin and M.I. Halliday et al., 1993. Adsorbents as antiendotoxin agents in experimental colitis. Gut, 34: 51-55. PMID: 8432452
Giadinis, N.D., E. Papadopoulos, N. Panousis, M. Papazahariadou and S.Q. Lafi et al., 2007. Effect of halofuginone lactate on treatment and prevention of lamb cryptosporidiosis: An extensive field trial. J. Vet. Pharmacol. Therapeut., 30: 578-582.

DOI: 10.1111/j.1365-2885.2007.00900.x

Giadinis, N.D., E. Papadopoulos, N. Panousis, M. Papazahariadou and S.Q. Lafi et al., 2008. Efficacy of halofuginone lactate for the treatment and prevention of cryptosporidiosis in goat kids: An extensive field trial. Small Ruminant Res., 76: 195-200. DOI:10.1016/j.smallrumres.2008.01.007

Gookin, J.L., M.G. Levy, J.M. Law, M.G. Papich and M.F. Poore et al., 2001. Experimental infection of cats with Tritrichomonas foetus. Am. J. Vet. Res., 62: 1690-1697. DOI: 10.2460/ajvr.2001.62.1690

Gookin, J.L., S.K. Nordone and R.A. Argenzio, 2002. Host responses to Cryptosporidium infection. J. Vet. Intern. Med., 16: 12-21. DOI: 0891-6640/02/1601-0002

Grinberg, A., A. Markovics, J. Galindez, N. Lopez-Villalobos and A. Kosak et al., 2002. Controlling the onset of natural cryptosporidiosis in calves with paromomycin sulphate. Vet. Rec., 151: 606-608. PMID: 12463536

Grinberg, A., W.E. Pomroy, R.A. Squires, A. Scuffham and A. Pita et al., 2011. Retrospective cohort study of an outbreak of cryptosporidiosis caused by a rare Cryptosporidium parvum subgenotype. Epidemiol. Infect., 139: 1542-1550. DOI: $10.1017 / \mathrm{S} 0950268810002499$

Holmberg, S.D., A.C. Moorman, J.C. Von Bargen, F.J. Palella and M.O. Loveless et al., 1998. Possible effectiveness of clarithromycin and rifabutin for cryptosporidiosis chemoprophylaxis in HIV disease. Jama, 279: 384-386. DOI: 10.1001/jama.279.5.384

Hotchkiss, E.J., J.A. Gilray, M.L. Brennan, R.M. Christley and L.J. Morrison et al., 2015. Development of a framework for genotyping bovine-derived Cryptosporidium parvum, using a multilocus fragment typing tool. Parasites Vectors, 8: 500-500. DOI: $10.1186 / \mathrm{s} 13071-015-1107-8$

Huang, M.Z., J. Li, L. Guan, D.Q. Li and X.M. Nie et al., 2015. Therapeutic effects of acetylspiramycin and garlicin on cryptosporidiosis among drug users. Int. J. Parasitol. Drugs Resistance, 5: 185-190. DOI: 10.1016/j.ijpddr.2015.09.002

Jarvie, B.D., L.A. Trotz-Williams, D.R. McKnight, K.E. Leslie and M.M. Wallace et al., 2005. Effect of halofuginone lactate on the occurrence of Cryptosporidium parvum and growth of neonatal dairy calves. J. Dairy Sci., 88: 1801-1806. DOI: $10.3168 /$ jds.S0022-0302(05)72854-X

Joachim, A., T. Krull, J. Schwarzkopf and A. Daugschies, 2003. Prevalence and control of bovine cryptosporidiosis in German dairy herds. Vet. Parasitol., 112: 277-288. DOI: $10.1016 / \mathrm{S} 0304-4017(03) 00006-2$ 
Johnson, E.H., J.J. Windsor, D.E. Muirhead, G.J. King and R. Al-Busaidy, 2000. Confirmation of the prophylactic value of paromomycin in a natural outbreak of caprine cryptosporidiosis. Vet. Res. Commun., 24: 63-67. DOI: $10.1023 / \mathrm{A}: 1006381522986$

Jurkic, L.M., I. Cepanec, S.K. Pavelić and K. Pavelić, 2013. Biological and therapeutic effects of orthosilicic acid and some ortho-silicic acid-releasing compounds: New perspectives for therapy. Nutrit. Metabolism, 10: 2-2. DOI: 10.1186/1743-7075-10-2

Klein, P., 2008. Preventative and therapeutic efficacy of halofuginone-lactate against Cryptosporidium parvum in spontaneously infected calves: A centralized, randomized, double-blind, placebo-controlled study. Vet. J., 177: 429-431. DOI: 10.1016/j.tvj1.2007.05.007

Koudela, B. and V. Jiří, 1997. Experimental cryptosporidiosis in kids. Vet. Parasitol., 71: 273-281. DOI: 10.1016/S0304-4017(97)00024-1

Kumar, S., G. Das, S. Nath and M. Nakul, 2015. Occurrence of Cryptosporidiosis in neonatal buffalo calves and its treatment. Intas. Polivet., 16 : 99-101.

Lallemond, M., A. Villeneuve and J. Belda and P. Dubreuil, 2006. Field study of the efficacy of halofuginone and decoquinate in the treatment of cryptosporidiosis in veal calves. Vet. Rec., 159: 672-677.

DOI: $10.1136 / v r .159 .20 .672$

Laurent, F., D. McCole, L. Eckmann and M.F. Kagnoff, 1999. Pathogenesis of Cryptosporidium parvum infection. Microbes Infect., 1: 141-148.

Leggo, P.J., B. Ledésert and G. Christie, 2006. The role of clinoptilolite in organo-zeolitic-soil systems used for phytoremediation. Sci. Total Environ., 363: 1-10. DOI: 10.1016/j.scitotenv.2005.09.055

Leung, S., S. Barrington, Y. Wan, X. Zhao and B. El-Husseini, 2007. Zeolite (clinoptilolite) as feed additive to reduce manure mineral content. Bioresource Technol., 98: 3309-3316. DOI: 10.1016/j.biortech.2006.07.010

Lindsay, D.S., K.M. Woods and S.J. Upton and B.L. Blagburn, 2000. Activity of decoquinate against Cryptosporidium parvum in cell cultures and neonatal mice. Vet. Parasitol., 89: 307-311. PMID: 10799844

Mancassola, R., A. Richard and M. Naciri, 1997. Evaluation of decoquinate to treat experimental cryptosporidiosis in kids. Vet. Parasitol., 69: 31-37. PMID: 9187027

Mancassola, R., J.M. Reperant, M. Naciri and C. Chartier, 1995. Chemoprophylaxis of Cryptosporidium parvum infection with paromomycin in kids and immunological study. Antimicrob. Agents Chemother, 39: 75-78. DOI: 10.1128/AAC.39.1.75

Masamha, B., C.T. Gadzirayi and I. Mukutirwa, 2010. Efficacy of Allium sativum (garlic) in controlling nematode parasites in sheep. In. J. Applied Res. Vet. Med., 8: 161-9.
Masood, S., A. Maqbool, U.J. Khan, Z.I. Chaudhry and A.A. Anjum, 2013. Anti-cryptosporidium activity of albendazole, metronidazole and paromomycin in experimentally infected cattle. Pak. J. Zool., 45: 935-940. DOI: 0030-9923/2013/0004-0935

McCole, D.F., L. Eckmann, F. Laurent and M.F. Kagnoff, 2000. Intestinal epithelial cell apoptosis following Cryptosporidium parvum infection. Infect. Immun., 68: 1710-1713.

DOI: $10.1128 /$ IAI.68.3.1710-1713.2000

Moore, D.A., E.R. Atwill, J.H. Kirk, D. Brahmbhatt and L.H. Alonso et al., 2003. Prophylactic use of decoquinate for infections with Cryptosporidium parvum in experimentally challenged neonatal calves. J. Am. Vet. Med. Assoc., 223: 839-845. PMID: 14507102

Naciri, M. and P. Yvore, 1989. Efficite du lactate d'halofuginone dans le traitment de le cryptosporidiose chez l'agneau [Efficacy of halofuginone lactate on the treatment of cryptosporidiosis of lambs]. Rec. Med. Vet. Ec. Alfort., 165: 823-823.

Nasir, A., M. Avais, M.S. Khan, J.A. Khan and S. Hameed et al., 2013. Treating Cryptosporidium parvum infection in calves. J. Parasitol., 99: 715-717. DOI: $10.1645 / 12-42.1$

O'Handley, R.M. and M.E. Olson, 2006. Giardiasis and cryptosporidiosis in ruminants. Vet. Clin. Food Anim. Pract., 22: 623-643. DOI: 10.1016/j.cvfa.2006.07.002

Panciera, R.J., R.W. Thomassen and F.M. Garner, 1971. Cryptosporidial infection in a calf. Vet. Pathol., 8: 479-484.

Paraud, C., I. Pors, J.P. Journal, P. Besnier and L. Reisdorffer et al., 2011. Control of cryptosporidiosis in neonatal goat kids: Efficacy of a product containing activated charcoal and wood vinegar liquid (Obionekk ${ }^{\circledR}$ ) in field conditions. Vet. Parasitol., 180: 354-357.

DOI: 10.1016/j.vetpar.2011.03.022

Pegues, A.S., S.S. Sofer, R.E. McCallum and L.B. Hinshaw, 1979. The removal of $14 \mathrm{C}$ labeled endotoxin by activated charcoal. Int. J. Artificial Organs, 2: 153-158. PMID: 381215

Petermann, J., C. Paraud, I. Pors and C. Chartier, 2014. Efficacy of halofuginone lactate against experimental cryptosporidiosis in goat neonates. Vet. Parasitol., 202: 326-329. DOI: 10.1016/j.vetpar.2014.02.027

Platts-Mills, J.A., S. Babji, L. Bodhidatta, J. Gratz and R. Haque et al., 2015. Pathogen-specific burdens of community diarrhoea in developing countries: A Multisite birth cohort study (MAL-ED). Lancet Glob Health, 3: 564-75.

DOI: $10.1016 / \mathrm{S} 2214-109 \mathrm{X}(15) 00151-5$ 
Redman, D.R. and J.E. Fox, 1993.The effect of varying levels of Deccox on experimental Cryptosporidia infections in Holstein bull calves. Proc. Am. Assoc. Bov. Pract., 26: 157-159.

Rehg, J.E., 1991. Activity of azithromycin against cryptosporidia in immunosuppressed rats. J. Infect. Dis., 163: 1293-1296. DOI: 10.1093/infdis/163.6.1293

Ritchie, D.J. and E.S. Becker, 1994. Update on the management of intestinal cryptosporidiosis in AIDS. Ann. Pharmacother., 28: 767-778. DOI: $10.1177 / 106002809402800615$

Robertson, L.J., C. Björkman, C. Axén and R. Fayer, 2013. Cryptosporidiosis in Farmed Animals. In: Cryptosporidium: Parasite and Disease, Cacciò, S.M. and G. Widmer (Eds.), Springer Science and Business Media, Vienna, ISBN-10: 3709115620.

Ryan, U. and N. Hijjawi, 2015. New developments in Cryptosporidium research. Int. J. Parasitol, 45: 367-373. DOI: 10.1016/j.ijpara.2015.01.009

Ryan, U., A. Zahedi and A. Paparini, 2016. Cryptosporidium in humans and animals-a one health approach to prophylaxis. Parasite Immunol., 38: 535-547. DOI: 10.1111/pim. 12350

Ryan, U., R. Fayer and L. Xiao, 2014. Cryptosporidium species in humans and animals: Current understanding and research needs. Parasitology, 141: 1667-1685. DOI: $10.1017 / \mathrm{S} 0031182014001085$

Sahu, B.D. and S.K. Maiti, 2015. Comparative efficacy of nitazoxanide and sulphadimidine in the treatment of cryptosporidiosis in bovine calves. J. Anim. Res., 5: 183-183. DOI: 10.5958/2277-940X.2015.00029.7

Schnyder, M., L. Kohler, A. Hemphill and P. Deplazes, 2009. Prophylactic and therapeutic efficacy of nitazoxanide against Cryptosporidium parvum in experimentally challenged neonatal calves. Vet. Parasitol., 160: 149-154. DOI: 10.1016/j.vetpar.2008.10.094

Schwabe, C.W., 1969. Veterinary Medicine and Human Health. 2nd Edn., Williams and Wilkins Co., Baltimore Williams and Wilkins, pp: 713.

Shafiq, M.A.B., A. Maqbool, U.J. Khan, M. Lateef and M. Ijaz, 2015. Prevalence, water borne transmission and chemotherapy of cryptosporidiosis in small ruminants. Pak. J. Zool., 47: 1715-1721.

Shahiduzzaman, M. and A. Daugschies, 2012. Therapy and prevention of cryptosporidiosis in animals. Vet. Parasitol., 188: 203-214.

DOI: $10.1016 /$ j.vetpar.2012.03.052
Theodos, C.M., J.K. Griffiths, J. D’Onfro, A. Fairfield and S. Tzipori, 1998. Efficacy of nitazoxanide against Cryptosporidium parvum in cell culture and in animal models. Antimicrob. Agents Chemother, 42: 1959-1965. PMID: 105716

Thompson, R.C.A., M.E. Oslon, G. Zhu, S. Enomoto and M.S. Abrahamsen et al,, 2005. Cryptosporidium and cryptosporidiosis. Adv. Parasit., 59: 77-158. DOI: $10.1016 / \mathrm{S} 0065-308 \mathrm{X}(05) 59002-\mathrm{X}$

Tzipori, S. and H. Ward, 2002. Cryptosporidiosis: Biology, pathogenesis and disease. Microbes Infect., 4: 1047-1058. DOI: 10.1016/S1286-4579(02)01629-5

Ulutas, B., H. Voyvoda, K. Ural, H. Erdogan and C. Dinler et al., 2015. Clinoptilolite decreases severity and duration of oocyte shedding in lambs infected with Cryptosporidium parvum: Preliminary results. Proceedings of the International Congress, One World-One Health-One Vision, Oct. 14-16, Sarajevo, Bosnia and Herzegovina, pp: 48-49.

Viel, H., H. Rocques, J. Martin and C. Chartier, 2007. Efficacy of nitazoxanide against experimental cryptosporidiosis in goat neonates. Parasitol. Res., 102: 163-166. DOI: 10.1007/s00436-007-0744-z

Villacorta, I., J.E. Peters, E. Vanopdenbosch, E. Ares-Mazás and H. Theys, 1991. Efficacy of halofuginone lactate against Cryptosporidium parvum in calves. Antimicrob. Agents Chemother, 35: 283-287. PMID: 244992

Viu, M., J. Quılez, C. Sánchez-Acedo, E. Del Cacho and F. López-Bernad, 2000. Field trial on the therapeutic efficacy of paromomycin on natural Cryptosporidium parvum infections in lambs. Vet. Parasitol., 90: 163-170. DOI: 10.1016/S0304-017(00)00241-7

Watarai, S., M. Tana and Koiwa, 2008. Feeding activated charcoal from bark containing wood vinegar liquid (Nekka-Rich) is effective as treatment for cryptosporidiosis in calves. J. Dairy Sci., 91: 1458-1463. DOI: $10.3168 /$ jds.2007-0406

Weber, S.E., C. Lippuner, S. Corti, P. Deplazes and M. Hässig, 2016. Clinical epidemiology of cryptosporidiosis in calves. Schweizer Archiv für Tierheilkunde. DOI: 10.17236/sat00062 